\title{
FURTHER GROWTH OF ITERATED ENTIRE FUNCTIONS-I
}

\author{
RATAN KUMAR DUTTA
}

Abstract. In this paper we study the comparative growth of iterated entire functions and generalise some earlier results.

Mathematics subject classification (2010): 30D35.

order.

Keywords and phrases: entire functions, growth, iteration, order, lower order, $p$-th order, lower $p$-th

\section{REFERENCES}

[1] J. CLunIE, The composition of entire and meromorphic functions, Mathematical essays dedicated to A. J. Macintyre, Ohio Univ. Press, 1970, 75-92.

[2] R. K. DuTTA, Further growth of iterated entire functions, Communicated.

[3] W. K. Hayman, Meromorphic Functions, Oxford University Press, 1964.

[4] B. K. LAhiri AND D. BAnerJeE, Relative fix points of entire functions, J. Indian Acad. Math. 19, 1 (1997), 87-97.

[5] I. LAHIRI, Growth of composite integral functions, Indian J. Pure Appl. Math. 20, 9 (1989), 899-907.

[6] I. LAHIRI AND D. K. Sharma, Growth of composite entire and meromorphic functions, Indian J. Pure Appl. Math. 26, 5 (1995), 451-458.

[7] K. NiINO AND C. C. YANG, Some growth relationships on factors of two composite entire functions, factorization theory of meromorphic functions and related topics, Marcel Dekker Inc. (New York and Basel), 1982, 95-99.

[8] D. SATO, On the rate of growth of entire functions of fast growth, Bull. Amer. Math. Soc. 69 (1963), 411-414.

[9] A. P. SingH, Growth of composite entire functions, Kodai Math. J. 8 (1985), 99-102.

[10] A. P. Singh AND M. S. BAloria, On maximum modulus and maximum term of composition of entire functions, Indian J. Pure Appl. Math. 22, 12 (1991), 1019-1026.

[11] G. D. Song AND C. C. YANG, Further growth properties of composition of entire meromorphic functions, Indian J. Pure Appl. Math. 15, 1 (1984), 67-82.

[12] G. VAliron, Lectures on the general theory of Integral functions, Chelsea Publishing Company, 1949.

[13] C. C. YANG AND H. X. YI, Uniqueness Theory of Meromorphic Functions, Kluwer Academic Publishers and Science Press, Beijing, 2003. 